\title{
Divorce And Its Impact On Families
}

\author{
Shamim Soomro \\ Department of Social Work \\ University of Sindh, Jamshoro \\ \& \\ Misbah B. Qureshi \\ Institute of Women Development Studies \\ University of Sindh, Jamshoro
}

\begin{abstract}
This paper discusses the issue of divorce within the context of Pakistani society. It introduces the reader to the definition and concept of divorce and shares some of the national and global statistics regarding the topic of divorce. Then it progresses to highlight the various reasons that lead to the annulment of marriage. These reasons may be economic, social, cultural, personal and/or a combination of all these. The paper then discusses the impact of divorce on the spouses, the children and all those who may be affected by the situation. The paper also discusses some ways to resolve marital conflicts so that they may be solved without resorting to the option of divorce. In the end, it highlights some ways to lessen the adverse impact of divorce on the parties concerned.
\end{abstract}

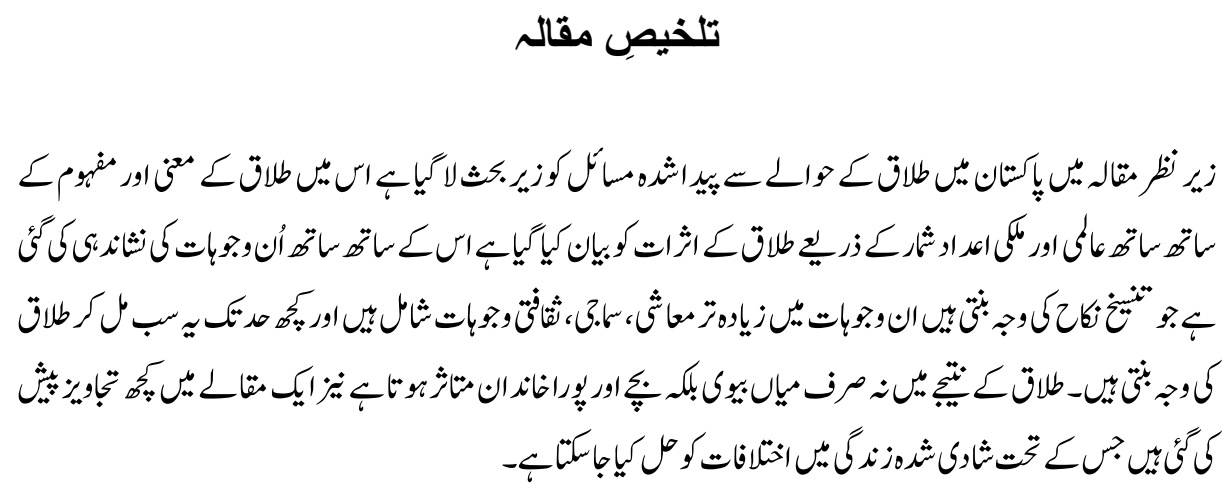

\section{Introduction}

Divorce, defined in simple terms, is the termination of marriage. It is the final cessation of a marriage that results in the cancellation of all legal obligations and responsibilities of marriage. Laws regarding divorce may vary across countries; however, in a majority of countries, divorce requires authorization of a legal authority such as court. The entire process of divorce may also include concerns such as alimony, child custody and support, division of property, etc. 
Recent years have witnessed a rise in divorce rates around the world. The family structure is disintegrating worldwide at an alarming rate and the issue has led to many sociologists and other experts carry out several studies on the causes behind the phenomenon and the impact the increasing rates of divorce are having on the structure of the society and the affected people. Divorce is a complex event. Some of the sociological researches have focused on factors such as social class, race and age, (Mark A. Fine, 2005)while other researches have focused on psychological dimensions as well as personality characteristics.

There are many reasons that are contributing to the dissolution of marriages between the spouses, the busy and modern way of life one among many of such factors. According to statistics by The Office for National Statistics (2010), the divorce rates in England and Wales are up by 4.9 percent in 2010 compared to in 2009: with 11.1 per thousand people divorcing their spouse in 2010 as compared to 10.5 per thousand in 2009 . The situation in the United States of America is not much different either. According to Jennifer Baker of the Forest Institute of Professional Psychology in Springfield, Missouri, there is a 50 percent chance of first marriages ending in divorce. The figures rise to 67 percent for second marriages and 74 percent for third marriages. In Europe, the divorce rate has doubled from 1.0 per 1000 inhabitants in 1970 to 2.0 per 1000 inhabitants by $2008 .{ }^{1}$

\section{Divorce in Pakistani Society}

Until recent years, the word "divorce" has been associated with nothing less than a social taboo in the Pakistani society. This is mainly because majority of the society has been somewhat conservative and has regarded the concept of divorce as a social stigma that is to be avoided at all possible costs. In the past, the word "divorce" was almost unheard of and regarded as a shame brought upon a family's name. Because of the male dominance prevalent in most of the country, women did not want to have the label of divorce attached to their names as it meant that the rest of the society would consider the woman a social outcast and a burden on the family. At the time of marriage, a girl would be advised by her parents that she has to compromise in all the situations and not consider divorce even as an option. Lack of financial support, lack of family support and the hostile attitude of society towards a divorcee meant that the woman had to compromise and make her marriage work out at all costs.

However, in recent times, the trends have been undergoing a change. A large part of the once traditional society is becoming more and more modernized. The mind sets of people have been changing and the focus is shifting from collectivism to individualism. This change is most prominent in the urban cities of Pakistan where more and more women are opting for higher education and entering the workforce. Once they begin to earn their own livelihoods, they no longer are as completely dependent on their spouse for financial 
support as they once used to be. There is more focus on ensuring one's own happiness rather than satisfying the demands of the society. These changes are leading to an increase in divorce rates not only among the upper classes but also among middle and lower classes of the society. In the city of Lahore alone, more than 100 divorces are filed in courts daily. Between February 2005 and January 2008, approximately 75,000 divorce cases had been filed in the courts of Lahore. Between February 2008 and May 2011, this number had risen to 1, 24,141. In the city of Karachi, there are between 5000 and 6000 divorces every month. (Rao, 2011).

According to a survey carried out by Gilani Research Foundation: Gallup Pakistan in 2010, approximately 48 percent of Pakistanis believe the divorce rates have increased in the country. When asked about their viewpoint regarding whether they believe the rates of divorce have gone up in the last ten years, the following were the recorded results:

\begin{tabular}{|l|c|}
\hline Have the divorce rates & Percentage responding \\
\hline Increased? & 48 \\
\hline Decreased? & 19 \\
\hline Remained same? & 32 \\
\hline No response & 1 \\
\hline
\end{tabular}

Source: Gilani Poll (Gallup Pakistan 2010)

\section{Divorce in the Light of Islam}

Marriage is a beautiful gift that has been bestowed on mankind by God. It is the building block of a family and the foundation on which the entire structure of society stands. Hence, divorce not only causes this beautiful structure to disintegrate, but also leads to a great deal of emotional stress for both the spouses who have to go through the painful process of ending all hopes of a life and future together. Divorce is an act which has not been appreciated or encouraged by Islam, however, it has been made permissible in situations where there is no other option out. It has been considered a last resort when all other attempts have failed to make the marriage work. In the Holy Quran, Allah says marital issues should be resolved by the spouses through communication. Only as a last resort divorce should be considered an option but that also must be carried out with as much compatibility as possible. In case a wife is fearful of cruelty or abandonment on her spouse's part, she will not be blamed if she opts for an agreeable settlement between herself and the husband.According to the Holy Prophet (P.B.U.H.), divorce is the most unpleasant act among all the permitted acts by God. ${ }^{2}$ 


\section{Causes of Divorce in the Context of Pakistani Society}

A phenomenon that was once unheard of in traditional Muslim societies such as Pakistan, divorce is fast becoming a reality for many households. As mentioned earlier, the rapidly changing lifestyles of people and changing mindsets are among the most prominent reasons for this increase in the divorce rates. When asked what in their view were some of the main reasons responsible for causing a hike in divorce rates, the same set of people who replied that they thought the rates of divorce had increased in the past decade in the aforementioned survey by Gallup Pakistan had the following responses recorded: 48 percent of these people believe that the rates of divorce have increased because of dearth of tolerance, 33 percent believe that it is because of increasing distance from religion, 27 percent believe that it is due to the impact of western culture and the western influence on the Pakistani society, 12 percent believe that it is because of the women giving more importance to their careers and 9 percent believe that it is because of men taking lesser interest in their marital relationship and gradually losing all interest. The survey also revealed a significant insight: a higher percentage of urbanites (21 percent) as compared to rural areas (6 percent) hold women responsible for taking greater interest in their career and hence causing their marriage to fall apart. The survey was performed among a sample of 2698 men and women in rural and urban areas of the four provinces of Pakistan (Gallup Pakistan 2010).

Reasons for divorce may vary from household to household. There is no one cause for divorce. Several factors may combine to lead a marriage towards a divorce, and sometimes just one reason can also lead to the situation. In words of Larry Frolick, who practiced family law for twenty years in North America, "every divorce is unique like a snow flake" (Khurshid\&Khurshid, 2010).

In the context of Pakistani society, the reasons for divorce can be categorized into cultural, social, economic and personal factors. These factors are explained below:

\section{Cultural Factors}

The increasing influence of the western world on the Pakistani society is quite prominent nowadays. There is greater emphasis on the concept of 'individual choice' and marriage is no longer regarded as a 'sacred' institution that it once used to be. The society is becoming more and more secularized and liberalized and religion is losing its traditional importance in the society. This trend is more visible in the upper socio-economic classes of Pakistan where both the spouses place greater importance on their own individual happiness and if their counterpart fails in any way to provide a happy, satisfactory relationship, they become disenchanted with their marriage and opt to liberate themselves from the institution of marriage (Shaukat, 2008). This 'desacralization' of marriage is 
leading to divorce. Spouses no longer consider themselves to be obligated to making their marriage work. They do not consider it their religious responsibility anymore and it is no longer a matter of fulfilling their covenant to God (Cherlin, 2004). The greater emphasis on individualism means that spouses consider their marriage successful only as long as it fulfills their physical, psychological and personal goals and needs and helps them in achieving personal growth. If the marriage fails to meet these needs, then the husband and wife consider themselves justified in abandoning the marriage bond to find new partners who can deliver these needs in a better way (Amber, 2009).

This shift in the mindsets has subsequently led to a lack of tolerance. A lot more is expected from a marriage now and there is lesser tolerance for any challenges faced in the marriage. Couples are not as willing to make sacrifices and compromises as they were before. However, this cultural shift has enabled some women to escape abusive behaviors by their husbands and lead a torture-free life. These women are not considered as much of social outcasts they were some decades back.

\section{Economic Factors}

Greater economic independence of women has liberated these women from the traditional chains of dependence on their male counterparts for livelihood. More and more women are pursuing higher studies and entering the workforce. According to Daily Times (Shaukat, 2008), women constitute 14 percent of the workforce of the IT industry in Pakistan out of which 37 percent are currently working at mid-executive positions whereas 13 percent are occupying senior management positions in reputed local and multinational firms. This increasing participation of women in the workforce has provided them financial independence and in case of an unhappy marriage, they can afford to choose the option of divorce and earn for themselves and for those dependent on them such as children and old parents. Economic independence has also led to an evolving power relationship between the man and his wife. The husband is no longer the sole bread earner of the household, hence he is no more the sole decision-maker also. Power patterns are shifting from the husband to the wife and sometimes these changes can lead to disputes and instability in the household. In more serious cases when these differences become irreconcilable, they can lead to divorce.

\section{Social Factors}

The rapid modernization of the society is a major cause of increasing divorce rates. Exposure to new ideas and lifestyles has radically transformed the social norms of the society. Joint family system is getting less and less popular and there is a shifting trend towards nuclear families in almost all classes of the society. In this way, the traditional attitudes towards a family that were built upon the sanctity of marriage have been 
replaced by modern concepts of individualism and pursuit of happiness. Earlier, in joint family system, out of respect for the in-laws both the spouses were forced to make compromises in order to avoid disputes. In nuclear families, however, there are no such external forces in the way and no higher authorities to resolve disputes if they take place. Modernization has also diluted the concept of marriage as a permanent situation that is to be borne by either party no matter what. It has created many other options for the people and they don't feel obligated to stay in a marriage if it no longer makes them happy. The transformation of society from a traditional to a modernized place has also put additional pressures on the people. It has created new demands for a more luxurious lifestyle and a never ending thirst for the material goods. The race to obtain the best house, the best car etc. puts a strain on the sentimental attitudes towards marriage and makes it a means to obtaining material luxuries rather than being considered as an end in itself. Failure to succeed in these motives results in frustration and often leads to bitter disputes between the spouses. Materialism and consumerism have engulfed the traditional values attached to a marriage and people prefer possessions over relationships. These changing values and preferences are leading to troubled marriages, often resulting in divorce.

Another tradition prevailing in Pakistani society is the social pressure on women to marry young. Most of the women in rural and semi-urban areas are often pressurized by their families to marry against their choice. Illiterate, immature and unhappy, they are forced into marriages which often serve the family's interests at the expense of individual choice. These forced arranged marriages can result in divorce soon afterwards because the partners are totally unfamiliar with each other. Moreover, sometimes there is domestic violence involved because of no mutual respect among the spouses. Younger people are also often unable to cope with the pressures of married life (Menard, 2011).

In majority of the Pakistani society, childlessness is considered a valid reason for a man to marry a second or third time. In many cases where the woman is unable to provide a family with children, the man is often encouraged by his family to marry again. Sometimes the man also divorces the earlier wife since he considers her a financial burden and a useless entity since she cannot produce offspring. In some instances, the woman herself opts for divorce since she suffers unjust treatment by the husband. According to the 2009 U.N. Gender Development Index, Pakistan ranked $124^{\text {th }}$ out of a list of 155 nations. This index gauges the position of women in the society and this ranking clearly tells about the low status awarded to women in the society.

Poverty is another contributor. Increasing rates of inflation in Pakistan have pushed several people below the poverty line. According to a survey by the Benazir Income Support Programme (2012), 45.7 percent of the people in Pakistan ${ }^{3}$ reside below the poverty line. This situation of poverty combined with the upward social mobility puts 
extreme financial strain on the family and can lead to quarrels between the spouses when the husband is not able to fulfill the material demands of the wife.

\section{Personal Factors}

There are several personal factors that lead to divorce. Most of these factors stem from a mixture of cultural, social and economic issues. One such factor is infidelity on the part of a spouse. The extra marital affairs, when discovered, often result in an immediate collapse of the marriage. In some lower strata of the society where poverty and illiteracy prevail, such infidelity also causes violent reactions such as murder of the spouse or merciless beating. Another factor is drug abuse which is prevalent in all socioeconomic classes of the society. The drug addict, often the husband, engages frequently in domestic violence and in an unstable state of mind, divorces his wife. Sometimes the wife faces so much physical and mental abuse that she is left with no choice but to leave the husband and opt for khula. In some instances, egotistical issues come into play and both the spouses refuse to consider any other option except divorce.

\section{Legal Factors}

The introduction of Muslim Family Courts Amendment Ordinance in 2002 which called for a khula to be finalized in case the reconciliation failed and be carried out within the time duration of six months, female initiated divorce rate increased by 50 percent.

\section{Consequences of Divorce}

In today's society, divorce is no longer the rare and scandalous event that it once used to be. It is expected that about 50 percent of children and adolescents will experience the parents' divorce in their childhood. However, even though it is more common and less of a social taboo, it does not mean it does not create problems for the parties concerned. Divorce, although a necessity in some cases where marriage becomes an impossible option to continue, nevertheless creates significant problems for the spouses, children and the families concerned. In the context of Pakistani society, the following is the impact of divorce on the parties:

\section{Increased Poverty and Financial Pressure}

Divorce increases chances of poverty especially for the affected women and children (Davies \& Denton, 2001). Although the situation worldwide has improved due to more women entering the workforce, the problem is more evident in Pakistan where already more than 45 percent of the population resides below the poverty line. Divorce pushes the women further down the poverty lane because they not only have to support themselves 
but also their children and the entire burden falls on their shoulders instead of being shared by both the spouses. These women also become a financial burden on their parents. In most common custody arrangements, the children remain with the mother, so this increases the burden of responsibility on the women. In the urban societies nowadays, more women are pursuing degree education and hence they are somewhat able to find a job to support their dependents. However, for women with little or no education, job hunt becomes a depressing and sometimes impossible task. Moreover, inflationary pressures are increasing day by day and affording children's education, nutrition and daily needs and wants becomes a burden on the limited resources. According to research, remarriage is the primary means to overcoming the poverty resulting from divorce (Reilly, 2009). However, divorced women often have difficulty remarrying because of the social stigma attached to them in the Pakistani society. They no longer become the preferable choice for any prospective partner and are mostly shunned by the society as an outcast and objects to be pitied upon.

\section{Effect on Children}

A divorce is not an isolated phenomenon in itself. It leaves its most significant impact on the children. It affects them physically, emotionally and psychologically and may leave temporary and sometimes permanent effects on their behavior and character. Each child has a different personality and hence reacts in a different way. Generally, a child passes through the following stages in event of a divorce: in infancy, the child has little or no awareness of the situation and often translates the divorce as loss of a parent. At preschool age, the child has a tendency to think that the events are caused by his emotions and thoughts and hence considers divorce as his own fault. He tends to think that the divorce was caused by his naughtiness, for not being good and for not doing something right. The child then begins to blame himself. The situation is also aggravated by the fact that parents often do not explain the divorce to the children since they think they are too young to understand. At school age, the child forms a tendency to take sides in the situation and blames one of his parents for the separation. He becomes angry at one parent and sympathetic towards another. These reactions lead to negative and aggressive behavior towards one of the parents whom the child holds guilty for the divorce. In adolescence, the child or more accurately, the young adult either becomes too involved with the scenario or becomes too distant and detached from it (Maldonado).

Children's immediate reactions to the divorce include anger, shock, confusion, sadness and disbelief. Some children withdraw from company and suffer in silence whereas some throw tantrums and become uncontrollably angry and defiant. In most cases, the quality of life deteriorates for the children after the divorce. Because of economic difficulties afterwards, children may have to shift to a less costly school and compromise on lower quality of nutrition and luxuries. They run a risk of developing inferiority complex and become socially awkward. They are also more likely to suffer from loss of confidence 
and self-esteem. Divorce can give birth to lasting sensation of loneliness, yearning, anxiety, and regret that adversely affect the psychological and emotional well-being of the person (Kelly \& Emery, 2003).

Children whose parents are divorced have a greater likelihood than other children to fall victims to depression, worry and various other emotive problems, display behaviorrelated disorders such as hyperactivity, aggressiveness, fighting and hostility, commit offenses, perform worse in school and lose motivation for studying and experience relationship problems. Moreover, adults whose parents divorced during their childhood or teenage are more likely than adults whose parents remained together to achieve lower educational levels and remain unemployed from time to time and face economic hardships, to have marital troubles in their own lives often leading to divorce as well, and to declare a bleak and less fulfilling childhood when asked. In cases of remarriage, the children can suffer from maltreatment at the hands of the step-parent which can cause further depression and loss of self-esteem.

There is also a phenomenon called diminished parenting, which basically means that parents face various stresses after divorce themselves which makes them less effective as parents to their children and hence they are unable to treat their children with the same level of affection, care and concern as other parents. However, in cases where the marriage was a source of great stress for the children due to domestic violence, frequent quarrels, etc. then divorce can actually be a source of relief for the children as well as the parents. In such a situation, providing a loving environment to the children after divorce and taking extra care of their needs and desires is necessary to ensuring that the harmful effects of divorce are minimized and the children are able to move on with their lives with confidence and surety.

\section{Effects on the Spouses}

Divorce often results in severe depression for the man and woman. As described earlier, women may have to bear additional financial burdens following the annulment of marriage. Both the parties also have to experience emotional stress (Rotermann, 2007). In cases where one of the partners is abandoned because of infidelity on the part of the other partner, there can be a great deal of distress for the person leading to loss of self-esteem. The abandoned person's ego is shattered and the life ahead suddenly begins to appear bleak and uncertain. In some instances where the distress builds to such high levels that it results in depression, the person may also have to resort to medication. Drug abuse is a menace that can engulf such vulnerable people. Because drugs can provide temporary relief from life's troubles, the depressed partner can be tempted towards them. Already Pakistani society is rapidly falling victim to the menace of drug abuse. The cheap and 
easy availability of drugs and the prevalence of drug cartels throughout the country are contributing to this increase in drug addiction.

Unhappy marriages are in themselves a cause of great stress for the spouses, and divorce is sometimes the only solution. However, divorce does not improve the situation completely. In a society such as Pakistan, divorced people and especially divorced women are not looked upon with respect. They are considered a social outcast and unfortunate beings, and this attitude of the society does not help the situation at all. Such negative feelings can lead to various health problems as well (Dupre\& Meadows, 2007). The effects of divorce on the physical andpsychological health of the partners may vary with factors such as personal variation in age, gender, health, the quality of the marriage such as whether it was a fulfilling relationship and its duration. To gauge the consequences of divorce on the health of the spouse, depression and mental distress are the indicators that are most widely used for the purpose. Studies have shown that women are more vulnerable to falling victims to the disease of depression as compared to their male counterparts. On the other hand, men are more prone to physical ill-health following the divorce episode. Divorced men are also reported to have a higher risk of committing suicide and both partners have a higher risk of mortality compared to married couples. Women tend to internalize the stress resulting from a broken marriage and this is exhibited in the higher levels of anxiety and depression. Men more generally tend to externalize stress by indulging in practices that are detrimental to health such as excessive smoking and unhealthy eating. In more severe cases they may even turn to illegal drugs and cause even greater harm to their health. Moreover, the level of negative impact that divorce has on the spouses can also depend on factors such as the education and employment of the parties. In the context of Pakistan, for example, women with higher level of education are less likely to experience depression for prolonged periods of time because they can employ themselves in useful outdoor activities and gain social support from their network of friends and family. Illiterate women, on the other hand, are left isolated and may face financial difficulties after divorce because they are unable to find employment. This may be a reason why divorce rates in the upper strata of Pakistani society are on the rise because people have more options and coping mechanisms available.

Oppression of women sadly remains a reality in Pakistan. Many women find themselves trapped in an unhappy and abusive marriage and are unable to escape. Those who do manage to break free and obtain divorce are left in a helpless state of misery and disapproval by society. Research conducted by the Aurat Foundation in Pakistan which keeps track of issues faced by women in the country found that there were 608 cases of domestic violence reported to the police in 2009 as compared to 281 in 2008. Many cases go unreported. Violence in marriage may be at a high rate of up to 90 percent in Pakistan. $^{4}$ 


\section{Ways to Avoid Divorce by Finding Solutions to Marriage Problems}

Although divorce is a permissible act in Islam, it is still not encouraged and both the parties are urged to try their best to reconcile their differences in order to make the marriage work. They are advised to use communication to resolve their problems and in case they are unable to solve the issues themselves, they are advised to involve and take help from close family members. Marriage is a relationship that requires nurturing to be strengthened. According to researcher and author John Gottman, there are two types of marital problems: conflicts that can be resolved and conflicts that appear perpetual. Couples must be able to recognize the difference between these two types. ${ }^{5}$ Once they can tell the difference, they may be better able to tackle the issues. Solvable problems are situational problems and in order to resolve them, couples should try to start conversations without being critical or judgmental. They should share their problems with each other and find a common ground that they believe is the root of their troubles. Next, they should try to understand each other's situation and take each other's thoughts and feelings into consideration. It is important to make compromises in a relationship and partners must be tolerant of each other's shortcomings. They must realize that no person in the world is perfect and hence, it becomes necessary to accept the partner's flaws in order to compromise. In case of perpetual problems whose solution does not appear in clear sight, partners must first assess what exactly is it that they want out of their marriage and what is preventing them from fulfilling those dreams. Once the source of conflict is identified, the couple must sit down and engage in dialogue. It is important to be honest with each other and explain one's needs and desires. The issue must be dealt with a calm mind because heated arguments are not a solution; instead, such arguments can exacerbate the situation and make things worse. In more complicated cases, guidance should be sought from trusted family members or friends. A professional counselor may also be able to help out the couple.

\section{Conclusions}

Divorce is a phase of life that brings along many physical, emotional and psychological challenges with it. It is important to acknowledge these challenges and then work on lessening their adverse impacts on one's life. There are several reasons that couples may opt for divorce, such as economic, social, cultural and personal. Changing values and lifestyles and modernization are some of the major factors causing increase in divorce rates. Divorce has many consequences on the physical, emotional and economic wellbeing of the husband, wife and the children. In instances where divorce becomes unavoidable, all possible attempts must be made by the affected parties to lessen its impact. It is important to accept the reality and make attempt to move on with life. 


\section{Recommendations on Recovering from Divorce and Limiting its Negative Consequences}

Divorce may be the only solution if it is the only way to escape from a long suffering marriage. However, it comes with its consequences and usually the partners are the ones most strongly hit. It is important to heal oneself afterwards and prepare oneself for the life ahead. Divorce results in loss of financial, emotional and social support as well as of hopes, dreams and plans. It is important to maintain a social circle where one can share their feelings and ask for support. It is also important to remind oneself that the goal is to move forward. In case the partners experience depression, they must identify the symptoms and then try to overcome it with the help of a healthy diet, exercise and social gathering. Sometimes it may be important to busy themselves in some constructive activities in order to help them moving on with life. Divorce also has adverse effects on the children. Both the parents should try to explain the situation in the best possible way to them so that they are not misled into thinking things that are untrue. The mother and father must try to take extra care of the needs and desires of the children so that they do not fall victims to inferiority complex or any other psychological problem. In a society such as Pakistan where divorce is still considered a taboo among some classes, the person must have the determination to deal with the negative attitudes of the people. Being financially independent is one of the best ways to deal with this attitude. The woman, if she is already not working, may consider opting for a job so that she does not have to depend on her family for fulfilling her needs and is not considered a burden by them.

\section{End Notes}

1. Divorce Rate. (n.d). Retrieved October 17, 2012, from Divorcerate.org: http://www.divorcerate.org/

2. www.usc.edu/org/cmje/religious-texts/hadith/muslim/009-smt.php

3. jang.com.pk/thenews/jun2012-weekly/nos-10-06-2012/pol1.htm

4. www.unicef.org/pakistan/National_Report.pdf

5. psychcentral.com/.../7-research-based-principles-for-making-marriag...

\section{References}

Amber, A.-M. (2009). Divorce: Factors, Causes \& Consequences. The Vanier Institute of the Family.

Bronselaer, D.K. (2008). The Impact of Divorce on the Health Status of ex-partners. Arch Public Health, 168-186. 
Cherlin, A.J. (2004). The Deinstitutionalization of American Marriage. Journal of Marriage and Family, 848-861.

The Human Rights Commission (n.d). Divorce Deals a Cruel Blow to Pakistani Women. Retrieved January 17, 2012, from Pakistan Defence Forum: http://www.defence.pk/forums/social-issues-current-events/51826-devorce-dealscruel-blow-pakistai-women.html

Davies, S., \&Denton, M. (2001).The Economic Well-Being of Older Women Who Become Divorced or Separated in Mid and Later Life.

Dupre, M.E., \& Meadows, S. O. (2007).Disaggregating the Effects of Marital Trajectories on Health. Journal of Family Issues, 623-652.

Gallup Pakistan. (2010). Views on Divorce Rate in Pakistan. http:www.gallup.com.pk.

Kelly, J.B., \& Emery, R.E. (2003). Children's Adjustment Following Divorce: Risk and Resilience Perspectives. Family Relations, 352-362.

Khurshid, F., Khatoon, S., \&Khurshid, N. (2010).Personal, Social and Psychological Factors Leading Towards Divorce. Interdisciplinary Journal of Contemporary Research in Business, 500-513.

Maldonado, M. (n.d.).Divorce and its Effects on Children and Adolescents. Retrieved October 17, 2012, from Kansas Association of Infant and Early Childhood Mental Health: http://www.kaimh.org/files/divorce.pdf.

Mark A. Fine, J. H. (2005). Handbook of Divorce and Relationship Dissolution.Lawrence Erlbaum Associates.

Menard, F.-P.(2011, April). What Makes it Fall Apart? The Determinants of the Dissolution of Marriages and Common-Law Unions in Canada.McGill Sociological Review, pp.59-76.

Rao, I. (2011, June 26). Divorce Rates Climb. Retrieved October 16, 2012, form Pakistan Today: http://www/pakistantoday.com.pk/2011/06/26/city/lahore/divorce-ratesclimb/

Reilly, K. (209). The Economic Consequences of Divorce: The Role of Child Support, Labor Force Participation and Means Tested Transfers over time. 
Rotermann, M. (2007).Marital Breakdown and Subsequent Depression.

Shaukat, A. (2008, February 28). View: Pakistan's Divorce Trends. Retrieved October 16, 2012, from Daily Times: http://www.dailytimes.com.pk/default.asp.?page $=2008 \% 5$ Cstory_28-2$2008 \_p g 3 \_5$

Dr. Shamim Soomro is Chairperson in the Department of Social Work, Sindh University, Jamshoro.

Dr. Misbah B. Qureshi is Incharge \& Director in the Institute of Gender Studies, Sindh University Jamshoro. 